NASA/TM-2004-213181

\title{
Ultra High Voltage Propellant Isolators and Insulators for JIMO Ion Thrusters
}

Bruce A. Banks, James R. Gaier, and Ching-Cheh Hung Glenn Research Center, Cleveland, Ohio

Patty A. Walters, Ed Sechkar, Scott Panko, and Christina A. Karniotis QSS Group, Inc., Cleveland, Ohio 
Since its founding, NASA has been dedicated to the advancement of aeronautics and space science. The NASA Scientific and Technical Information (STI) Program Office plays a key part in helping NASA maintain this important role.

The NASA STI Program Office is operated by Langley Research Center, the Lead Center for NASA's scientific and technical information. The NASA STI Program Office provides access to the NASA STI Database, the largest collection of aeronautical and space science STI in the world. The Program Office is also NASA's institutional mechanism for disseminating the results of its research and development activities. These results are published by NASA in the NASA STI Report Series, which includes the following report types:

- $\quad$ TECHNICAL PUBLICATION. Reports of completed research or a major significant phase of research that present the results of NASA programs and include extensive data or theoretical analysis. Includes compilations of significant scientific and technical data and information deemed to be of continuing reference value. NASA's counterpart of peerreviewed formal professional papers but has less stringent limitations on manuscript length and extent of graphic presentations.

- TECHNICAL MEMORANDUM. Scientific and technical findings that are preliminary or of specialized interest, e.g., quick release reports, working papers, and bibliographies that contain minimal annotation. Does not contain extensive analysis.

- CONTRACTOR REPORT. Scientific and technical findings by NASA-sponsored contractors and grantees.
- CONFERENCE PUBLICATION. Collected papers from scientific and technical conferences, symposia, seminars, or other meetings sponsored or cosponsored by NASA.

- SPECIAL PUBLICATION. Scientific, technical, or historical information from NASA programs, projects, and missions, often concerned with subjects having substantial public interest.

- TECHNICAL TRANSLATION. Englishlanguage translations of foreign scientific and technical material pertinent to NASA's mission.

Specialized services that complement the STI Program Office's diverse offerings include creating custom thesauri, building customized databases, organizing and publishing research results ... even providing videos.

For more information about the NASA STI Program Office, see the following:

- Access the NASA STI Program Home Page at http://www.sti.nasa.gov

- E-mail your question via the Internet to help@sti.nasa.gov

- Fax your question to the NASA Access Help Desk at 301-621-0134

- Telephone the NASA Access Help Desk at 301-621-0390

- Write to:

NASA Access Help Desk

NASA Center for AeroSpace Information 7121 Standard Drive

Hanover, MD 21076 
NASA/TM-2004-213181

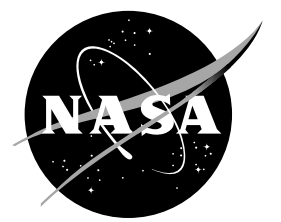

\section{Ultra High Voltage Propellant Isolators and Insulators for JIMO Ion Thrusters}

Bruce A. Banks, James R. Gaier, and Ching-Cheh Hung

Glenn Research Center, Cleveland, Ohio

Patty A. Walters, Ed Sechkar, Scott Panko, and Christina A. Karniotis QSS Group, Inc., Cleveland, Ohio

Prepared for the

40th Joint Propulsion Conference and Exhibit

cosponsored by the AIAA, ASME, SAE, and ASEE

Fort Lauderdale, Florida, July 11-14, 2004

National Aeronautics and

Space Administration

Glenn Research Center 


\section{Acknowledgments}

The authors gratefully acknowledge the structural analysis provided by Chris Hetman, Cleveland State University, performed under NASA Grant NCC3-1023.

Available from

NASA Center for Aerospace Information 7121 Standard Drive

Hanover, MD 21076
National Technical Information Service 5285 Port Royal Road Springfield, VA 22100

Available electronically at http:/ /gltrs.grc.nasa.gov 


\title{
Ultra High Voltage Propellant Isolators and Insulators for JIMO Ion Thrusters
}

\author{
Bruce A. Banks, ${ }^{*}$ James R. Gaier, ${ }^{\dagger}$ Ching-Cheh Hung ${ }^{*}$ \\ NASA Glenn Research Center, Cleveland, Ohio 44135 \\ Patty A. Walters,${ }^{\S}$ Ed Sechkar, ${ }^{\circledR}$ Scott Panko, ${ }^{\#}$ and Christina A. Karniotis** \\ QSS Group, Cleveland, Ohio 44135
}

\begin{abstract}
Within NASA's Project Prometheus, high specific impulse ion thrusters for electric propulsion of spacecraft for the proposed Jupiter Icy Moon Orbiter (JIMO) mission to three of Jupiter's moons: Callisto, Ganymede and Europa will require high voltage operation to meet mission propulsion. The anticipated $\sim 6,500$ volt net ion energy will require electrical insulation and propellant isolation which must exceed that used successfully by the NASA Solar Electric Propulsion Technology Readiness (NSTAR) Deep Space 1 mission thruster by a factor of $\sim 6$. Xenon propellant isolator prototypes that operate at near one atmosphere and prototypes that operate at low pressures ( $<100$ Torr) have been designed and are being tested for suitability to the JIMO mission requirements. Propellant isolators must be durable to Paschen breakdown, sputter contamination, high temperature, and high voltage while operating for factors longer duration than for the Deep Space 1 Mission. Insulators used to mount the thrusters as well as those needed to support the ion optics have also been designed and are under evaluation. Isolator and insulator concepts, design issues, design guidelines, fabrication considerations and performance issues are presented. The objective of the investigation was to identify candidate isolators and insulators that are sufficiently robust to perform durably and reliably during the proposed JIMO mission.
\end{abstract}

\section{Introduction}

The electrical isolation between spacecraft-potential ion thruster propellant tanks and the discharge chambers has always been a source of reliability and durability concern. Similarly, the need to mechanically support the thruster body and ion optics with high voltage differences from adjoining components represents a trade off challenge predominantly involving size, weight, structural considerations and durability. The NASA Solar Electric Propulsion Technology Readiness (NSTAR) program ion propulsion system used on the Deep-Space 1 spacecraft required xenon propellant isolation and insulation for potential differences of 1100 volts. ${ }^{1}$ The high voltage propellant isolators used consisted of hollow alumina cylinders containing seven segments of alumina rings separating eight stainless steel screens. The ends of the alumina tubing had brazed Kovar ceramic to metal end caps to bring in the

\footnotetext{
* Chief, Electro-Physics Branch, NASA Glenn Research Center, 21000 Brookpark Road, Cleveland, OH 44135

$\dagger$ Senior Scientist, Electro-Physics Branch, NASA Glenn Research Center, 21000 Brookpark Road, Cleveland, $\mathrm{OH} 44135$

† Senior Scientist, Electro-Physics Branch, NASA Glenn Research Center, 21000 Brookpark Road, Cleveland, OH 44135

$\S$ Propulsion Engineer, QSS Group, Inc, Glenn Research Center, 21000 Brookpark Road, Cleveland, OH 44135

I Senior Mechanical Engineer, QSS Group, Inc, Glenn Research Center, 21000 Brookpark Road, Cleveland, $\mathrm{OH} 44135$

\# Electrical Engineer, QSS Group, Inc, Glenn Research Center, 21000 Brookpark Road, Cleveland, OH 44135

** Research Engineer, QSS Group, Inc, Glenn Research Center, 21000 Brookpark Road, Cleveland, OH 44135
} 


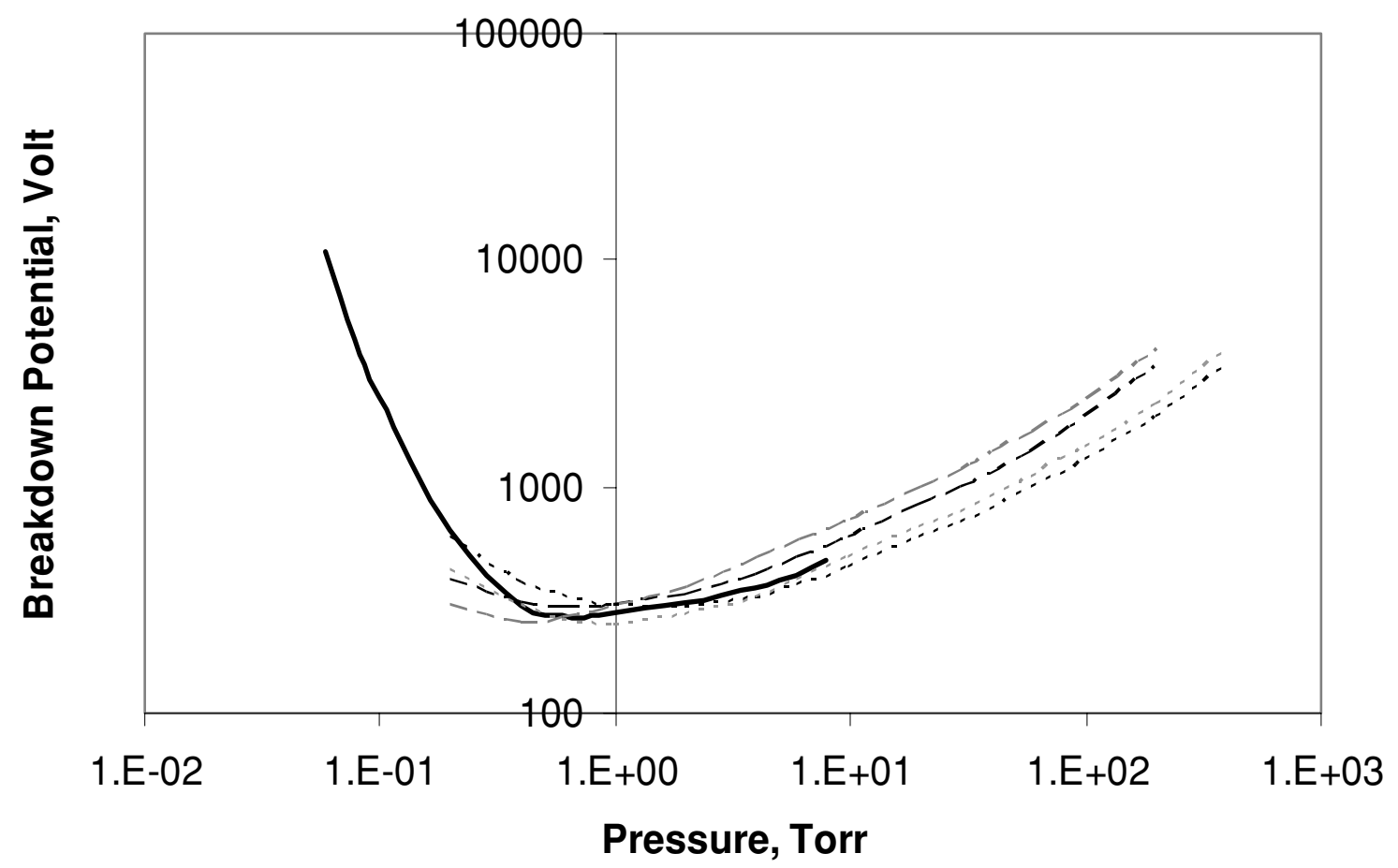

$S----H-b----H+b \quad \cdots \cdots \cdot H-S \cdots \cdots \cdot H+S$

Figure 1. Breakdown potential of Xe as a function of pressure across a 0.4 " gap based on the pressure $\times$ distance data from (S) Schonhuber ${ }^{2}$ and $(\mathrm{H})$ Hackam. $^{3}$ Hackam's data are represented for a $3.6 \mathrm{~cm}$ electrode (b) and a $1.7 \mathrm{~cm}$ electrode (s) with both the inner wire as the cathode (-) and as the anode (+).

xenon at spacecraft ground and exit it at high voltage. The xenon propellant flow was controlled upstream of the cathode and main isolators, resulting in low pressures within the isolators but not so low as to cause Paschen breakdown for the operating conditions used. For higher voltage isolators the Paschen curve needs to be reconsidered to assure operation without breakdown. Although the Paschen breakdown curve for Xe has been investigated by numerous researchers, a wide range of breakdown voltages exists for the same pressure distance products as shown in Fig. 1 depending partially upon the geometry used and other unknown causes. ${ }^{2-3}$

The measurements for Paschen breakdown, in Fig. 1, were all performed with much smoother surfaces than one would expect for the proposed JIMO mission. Thus, experimental testing appears warranted for the specific geometries being considered. The isolators in NSTAR were surrounded with overlapping stainless steel shadow shielding to prevent any line of sight arrival of sputtered conductive material from depositing on the surface of the alumina.

High voltage electrical insulators used in NSTAR consisted of similar but smaller alumina hollow cylinder with brazed Kovar ceramic to metal end caps which were threaded to attach the screen and accelerator grids to a mount ring at spacecraft ground. Double shadow shielding was also used on the insulators.

Some of the major challenges for the development of xenon propellant isolators and insulators for the JIMO project are the factors-higher requirements for electrical isolation voltages, hours of operation, and total xenon throughput in comparison to the NSTAR Deep Space 1 thruster. Loss of acceptable electrical isolation for either the isolators or the many insulators used to support the thruster body and/or ion optics would terminate operation of the thrusters. Table I compares the thruster parameters relevant to isolators and insulators assumed for design for the JIMO project with those of the NSTAR Extended Life Test (ELT) thruster. As can be seen from Table I, the greatly higher levels of expected voltage, duration of operation and implicit amount of sputtered material that will be generated by the JIMO thruster in both ground facility durability testing as well as on its in-space mission will require conservatism in the design of both the JIMO isolators and insulators to assure acceptable performance and reliability for the duration of operation required. 
Table I. Comparison of JIMO and NSTAR-ELT thruster operating parameters relevant to propellant isolator and insulators.

\begin{tabular}{|l|c|c|c|}
\hline \multicolumn{1}{|c|}{ Parameter } & JIMO & NSTAR-ELT & Ratio of JIMO/NSTAR-ELT \\
\hline Ion beam voltage, $\mathrm{V}$ & 6,500 & 1,100 & 5.9 \\
\hline Duration of operation, hours & 150,000 & 30,352 & 4.9 \\
\hline Ion beam current, $\mathrm{A}$ & 8 & 1.3 & 6.2 \\
\hline Xenon throughput, $\mathrm{kg}$ & 4000 & 235 & 17 \\
\hline
\end{tabular}

This paper reports the investigation of design issues and considerations used for the development of candidate propellant isolators and insulators for JIMO application.

\section{Apparatus and Procedure}

Knowing the design and success of the NSTAR-Deep Space I and ELT ion thrusters and the requirements for the proposed JIMO mission, design considerations and guidelines were developed with the intention of contributing to increased mission performance, durability, and reliability. The design assumptions and guidelines for Xe propellant isolators and insulators were:

1. 6,500 volt operation

2. 10,000 volt stand off for a safety factor of 1.5 above the operating condition

3. Shadow shielding gaps must exceed ion optics gap by 50\% to assure electrical breakdown will always occur between the ion optics rather than in the vicinity of the alumina surfaces

4. Shadow shielding for both the screen and accelerator ion optics insulators will be identical to allow the screen grid to be raised to the beam supply potential for flake clearing

5. Alumina used for Xe propellant isolators and insulators to be at least $97.6 \%$ pure $\mathrm{Al}_{2} \mathrm{O}_{3}$

6. $\sim 250 \mathrm{C}$ operation of isolators and insulators

7. $\sim 45$ standard cubic centimeters per minute $(\mathrm{sccm})$ Xe flow rate to discharge chamber and $5 \mathrm{sccm}$ to the cathode

8. Designs must include

- High pressure ( 1 atmosphere) compatible configurations

- Low pressure $(<100$ Torr) compatible configurations

9. Contamination tolerance

10. Structural integrity to tolerate applied loads from vibration and thermally induced stresses

11. Ceramic cylinder geometries to have length to diameter ratios less than or equal to NSTAR geometries for structural considerations relating to vibration and bending load tolerance

12. Able to be mounted on thruster body or ground potential housing.

The designs considered the following failure modes for Xe propellant isolators and insulators:

1. Breakdown in bulk ceramic

2. Paschen breakdown

3. Surface conductivity on internal or external surfaces due to

a. Contamination arriving from deposition from arcs caused by flakes floating into the shadow shield gap

b. Contamination transported to surface from bulk of the alumina

c. Sputter deposition of conductive species

d. Gaseous contaminants deposition

4. Contaminants surface transported from metals in contact with the ceramic surface

5. Mechanical failure of ceramic or ceramic to metal bonds as a result of

a. Mechanical stress during assembly

b. Launch vibration

c. Thermally induced stresses

6. Mechanical load carrying capacity

a. Tension

b. Torsion

c. Shear

d. Bending 
The criteria used for down selection of the propellant isolators and insulators to be investigated are listed below:

1. Durability to Paschen breakdown

2. Durability to external surface conductivity failure

3. Durability to internal surface conductivity failure

4. Durability to bulk ceramic conductivity failure

5. Durability to mechanical failure during launch vibration

6. Durability to mechanical failure from thermally induced stresses

7. Acceptability of overall size

8. Acceptability of overall mass (insulators only)

9. Acceptability of overall cost

10. Thermal expansion compliance to minimize stresses on ion optics (for insulators only)

11. Ability to operate at $<<1$ atmosphere to minimize propellant residuals (for high pressure isolators only)

12. Ability to operate at low upstream pressures (for low pressure isolators only)

Experimental and analytical evaluations of isolator and insulator concepts and prototypes has been conducted with testing initiated in a variety of facilities to both assess concepts and to test prototypes under vacuum. Figure 2 shows a photograph and schematic diagram of a Xe propellant isolator test facility constructed to perform high voltage leakage testing under thermal, propellant flow and low pressure environmental conditions. The alumina used for evaluation of Xe propellant isolators and insulators was at least $97.6 \%$ pure $\mathrm{Al}_{2} \mathrm{O}_{3}$. The facility is unique in that the pressure in the isolator is independent of the pressure surrounding the isolator of the cryopumped test chamber. Tungsten halogen lamps are used to provide heating of the isolators to simulate thruster operational temperatures.

To assure that Xe Paschen breakdown will not occur under all expected ground laboratory and in-space environmental conditions, a test facility was constructed to assess breakdown simulating coaxial shadow shields. Figure 3 shows pictures of that test facility.

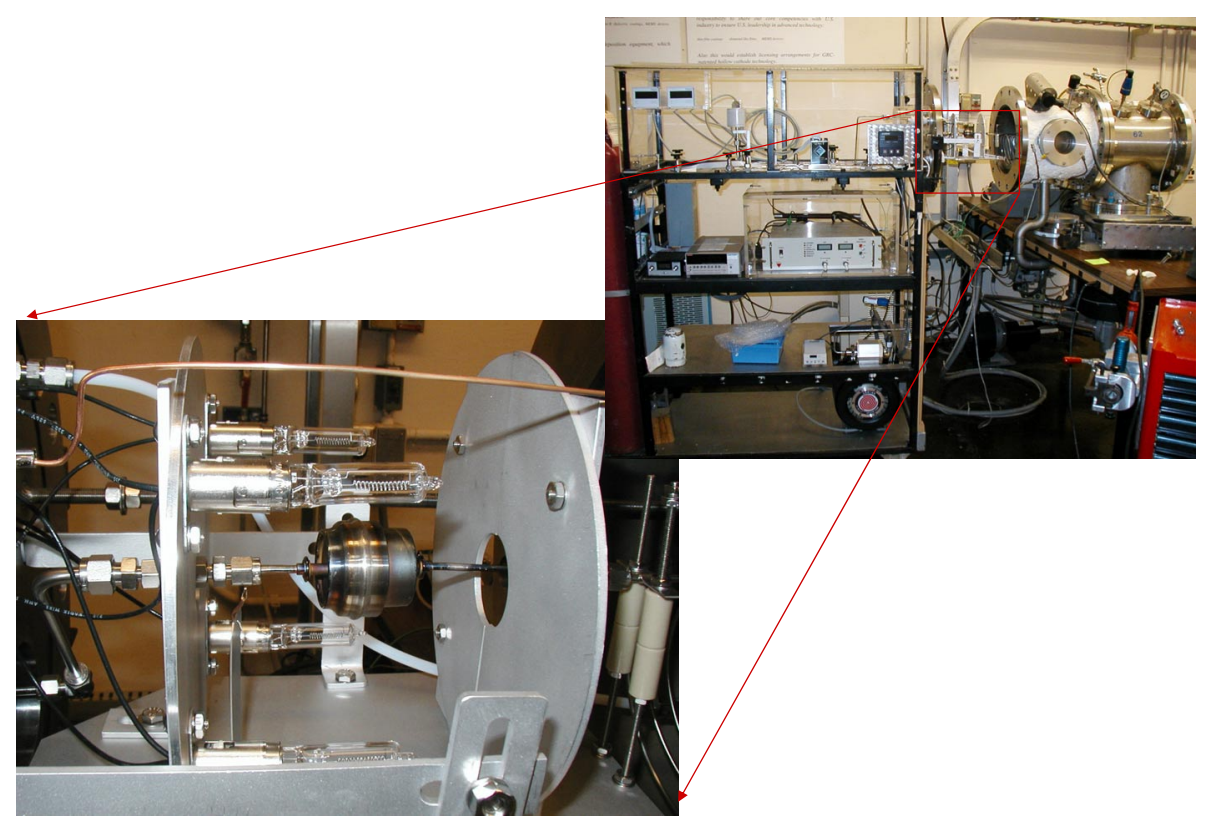

a. Photograph

Figure 2. Xenon propellant isolator test facility. 


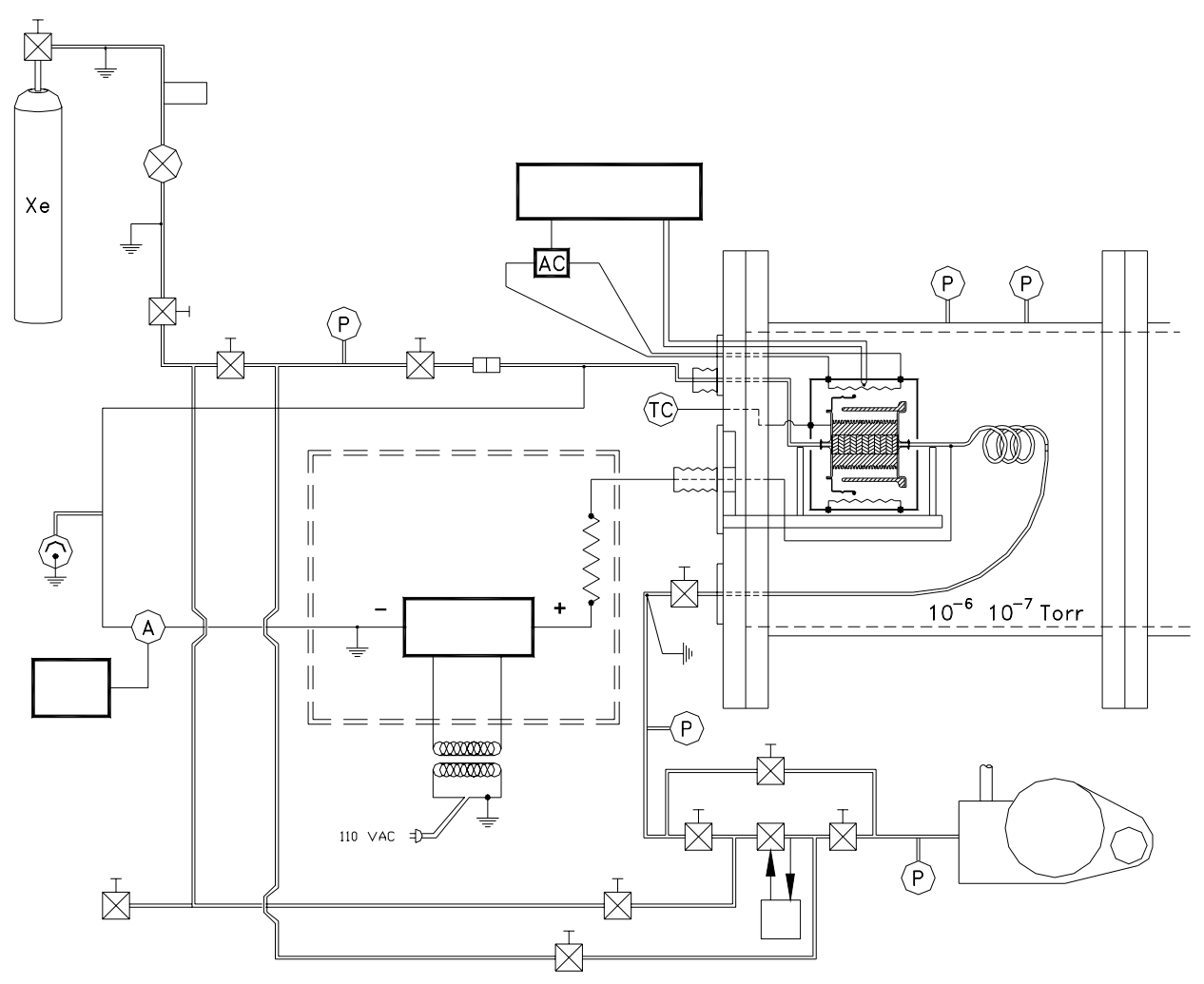

b. Schematic diagram

Figure 2. Xenon propellant isolator test facility (concluded).

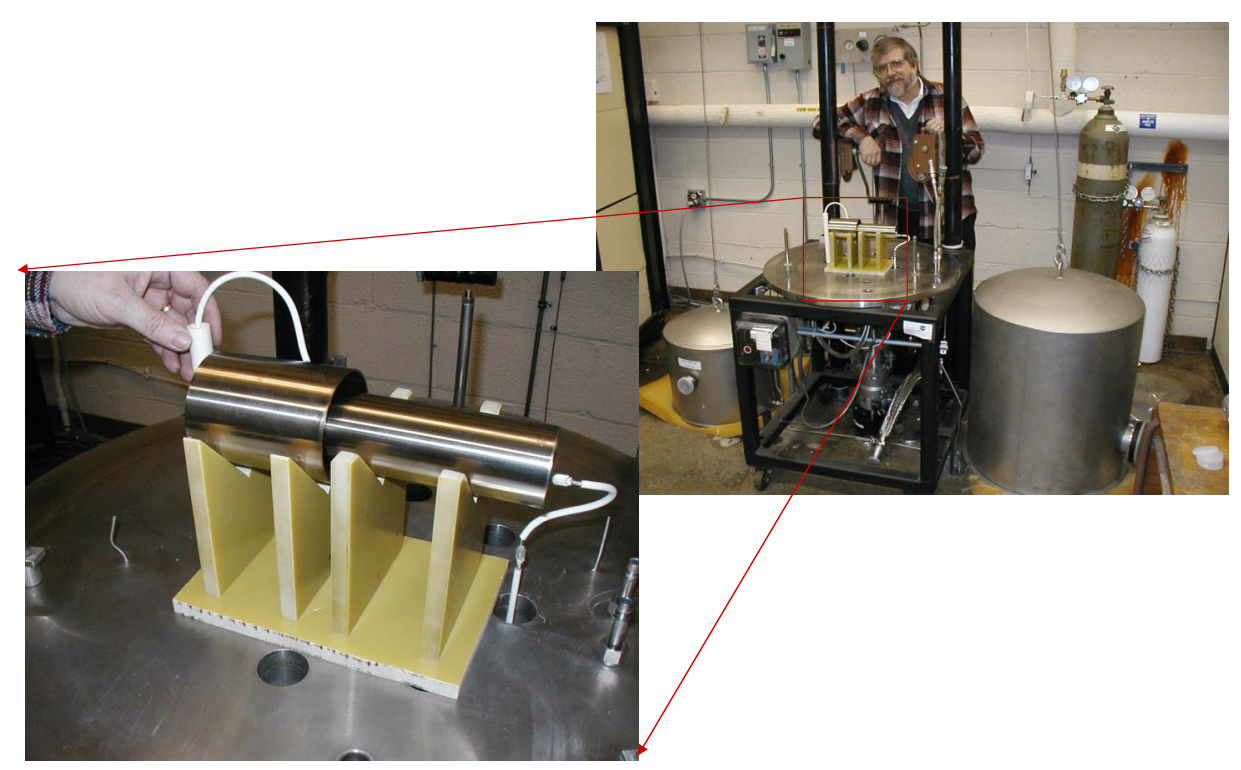

Figure 3. Paschen breakdown test facility. 




Figure 4. Isolator and insulator contamination test facility.

The assessment of the ability of the shadow shields and surface morphology of the isolators and insulators to tolerate an incoming flux of conducting condensable sputtered or pyrolyzed organic contaminant will be performed in a cryopumped vacuum facility which allows evaporation or sputter deposition of conductive materials such as carbon or metals as shown in Fig. 4. This facility also allows the isolator or insulators to be heated with tungsten halogen lamps to simulate thruster operating temperatures while measuring leakage current before and after impinging contaminants toward the isolators or insulators to purposely trying to contaminate their external surfaces.

\section{Results and Discussion}

\section{A. Xe Propellant Isolators}

The following types of Xe propellant isolators were down selected for fabrication and experimental evaluation.

1. Straight tube cryobrake

2. Wavy or grooved external surface straight tube cryobrake

3. Porous ceramic-filled core

4. Wavy or grooved external surface with porous ceramic-filled core

5. Internal spiral with porous fused-ceramic particles

6. Wavy or grooved external surface with internal spiral with porous fused-ceramic particles

7. Shielded negative terminal with porous fused-ceramic particle-filled core

8. Wavy or grooved external surface shielded negative terminal with porous fused ceramic particle filled core

The wavy or grooved external surface consists of saw cuts in the alumina with half round roots (to reduce stress concentrations). The saw cuts are approximately 4 times as deep as they are wide to provide an external surface path length that is approximately 3.7 times longer than the smooth surface isolator. Figure 5 is a picture of a wavy or grooved external surface isolator without and with shadow shielding which was configured in accordance to the design assumptions and guidelines in section II. 


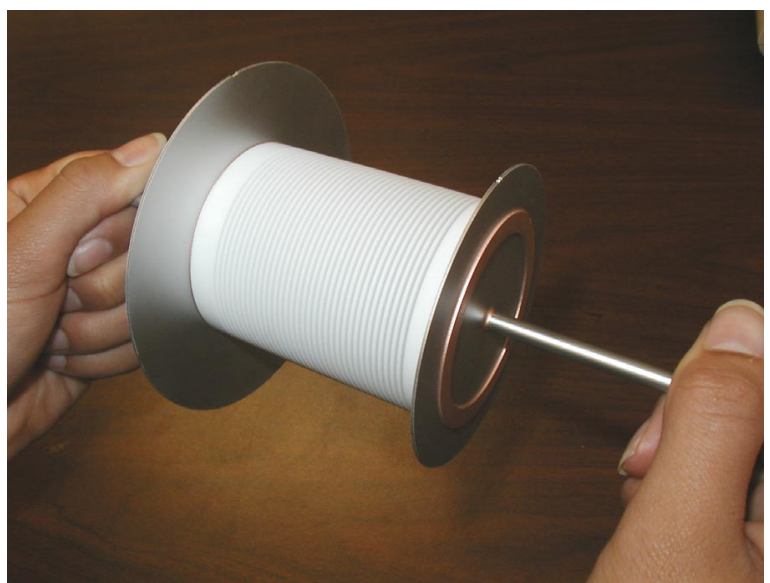

a. Without shadow shields

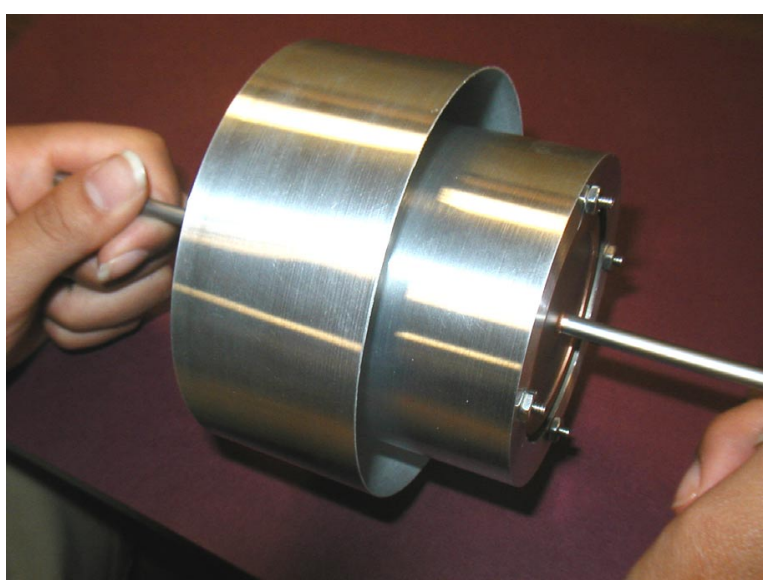

b. With shadow shields attached

Figure 5. Wavy or grooved external surface isolator

The straight tube cryobrake design would only be applicable for a high pressure isolator but would not be adequately long for a low pressure isolator. To enable electrical isolation at low pressures with an overall isolator length that is acceptably short to enable it to be structurally robust, a longer path length can be achieved by filling the isolator with a porous medium. The porous medium of choice would be made of alumina with pore sizes adequately small to attenuate electron avalanches from developing into arcs. The porosity also needs to be adequate to allow the required $\mathrm{Xe}$ flow with acceptable pressure drops across the isolator. Tests were conducted using various particle size alumina green stock (which would be fired to produce the final alumina) using air, at one atmosphere, to assess the dependence of particle fill size on breakdown strength. The particles cause the breakdown path to occur in random locations rather than making a track that may occur if any conductive material was sputtered during repeated arcing. Figure 6 shows three photos of sequential electrical breakdowns in a fused silica tube filled with 550 micron green stock particles indicating that the breakdown path varies.

The effect of particle size on Paschen breakdown at low pressure was explored for alumina green stock particles in air using the same fused silica tube technique to find if there is significant merit in filling the isolators with a porous insulating media. Figure 7 shows a plot of the breakdown voltage gradient as a function of particle size in air at 31.7 Torr with a $13.88 \mathrm{~mm}$ gap. Also shown on the plot is the breakdown voltage gradient for the same gap with no fill material. As can be seen there can be up to a factor of 3.3 increase in breakdown strength by filling the gap with fine (329 micron) particles. Loose particles can leave a void in the electric field gradient direction which would provide an easy ionization path through the isolator with no gain in field strength over a simple unfilled isolator. Thus, the porous media needs to be fused to the impervious outer cylinder to take advantage of the particles. A problem occurs if one fires an alumina green stock powder filling an alumina green stock cylinder. The typical shrinkage that occurs as a result of firing the bulk green stock of the bulk material is less than for the granular or powdered green stock. This causes voids to form down the length of the isolator as can be seen in Fig. 8. A solution to this problem appears to be to use a combination of green stock particles and already fired particles or microspheres to fill the green stock cylinder. The length of the isolator has a strong influence over the breakdown voltage as can be seen in Fig. 9 for 600 micron alumina microspheres at 31.7 Torr in air. 

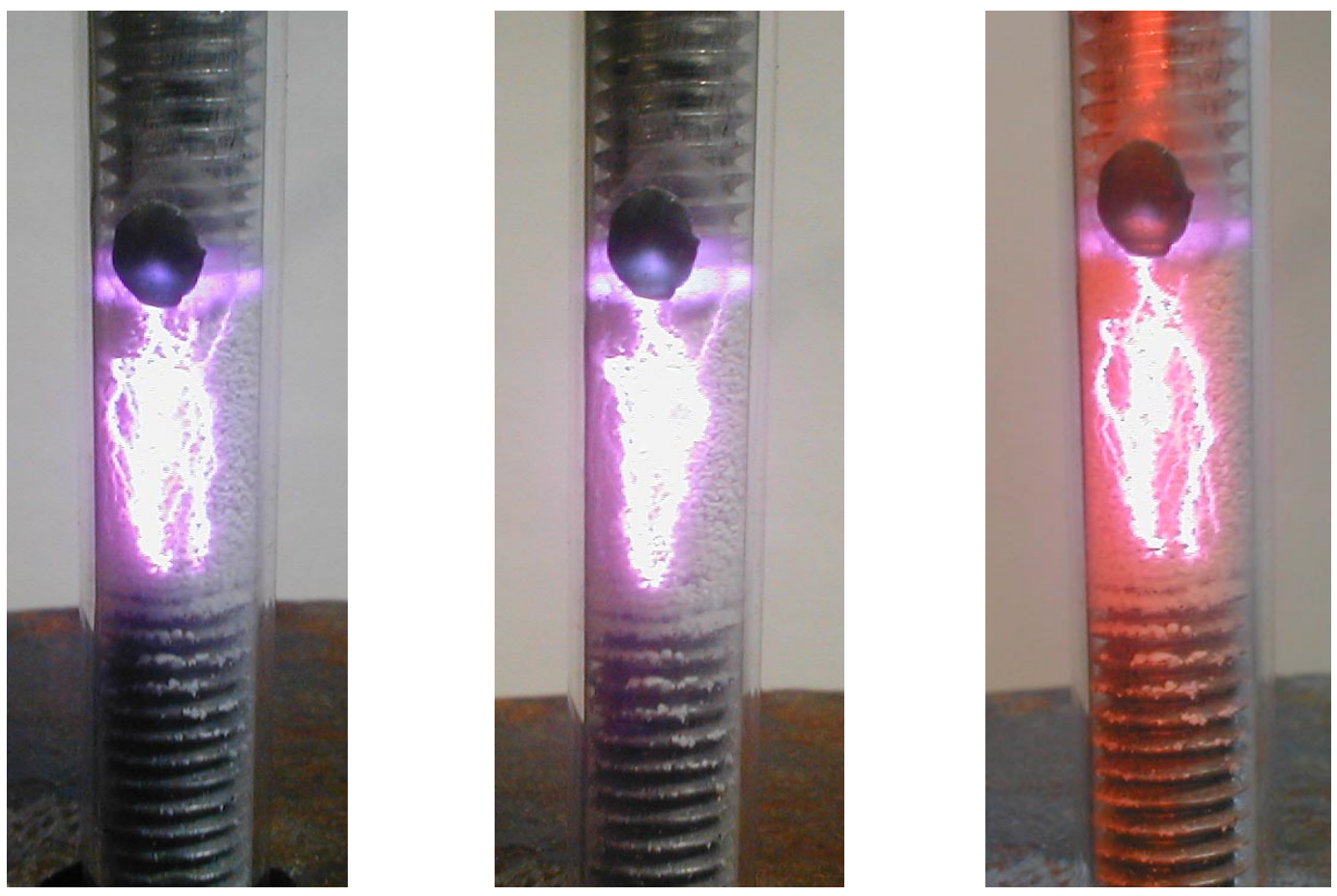

Figure 6. Electrical breakdown in air at one atmosphere in a fused silica tube filled with $\mathbf{5 5 0}$ micron alumina green stock particles.



Figure 7. Breakdown voltage gradient as a function of alumina particle size in air at 31.7 Torr with a $13.88 \mathrm{~mm}$ gap. 




Figure 8. Voids in porous ceramic-filled core alumina caused by excessive shrinkage of the green stock particles.

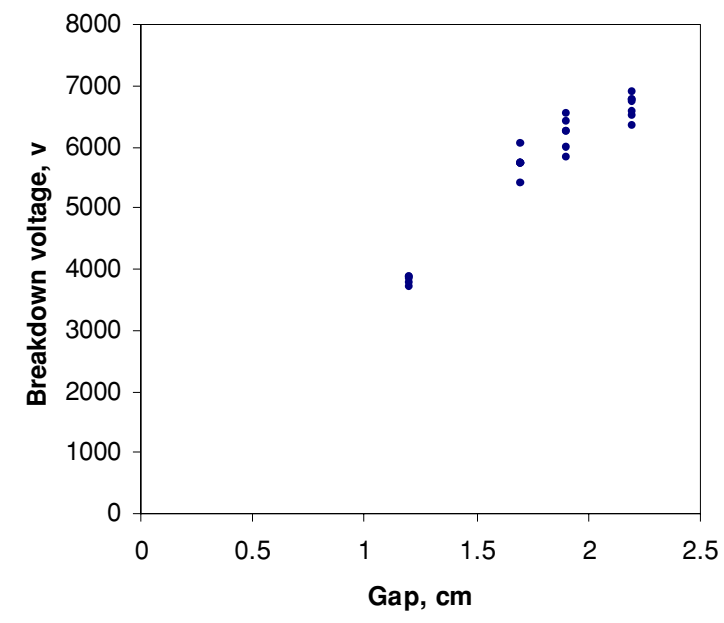

Figure 9. Breakdown voltage for 600 micron alumina microspheres at 31.7 Torr in air.

As can be seen from Fig. 9 there appears to be approximately a linear gain in breakdown strength as a function of gap length for the microsphere filled isolator as one would suspect from simple parallel gap Paschen breakdown behavior. The increase in path length provided by spherical particle filled isolators required for the initiation of Paschen breakdown is simply the shortest path length around hexagonally packed spheres and is $17 \%$ longer than for an unfilled isolator and independent of microsphere size. At the outer perimeter of a microsphere-filled isolator, the path length for electrical breakdown is simply the overall length and is not a tortuous path as in the hexagonally packed core. At this interface the path length is $\sim 83 \%$ of that of the core (see Fig. 10). 


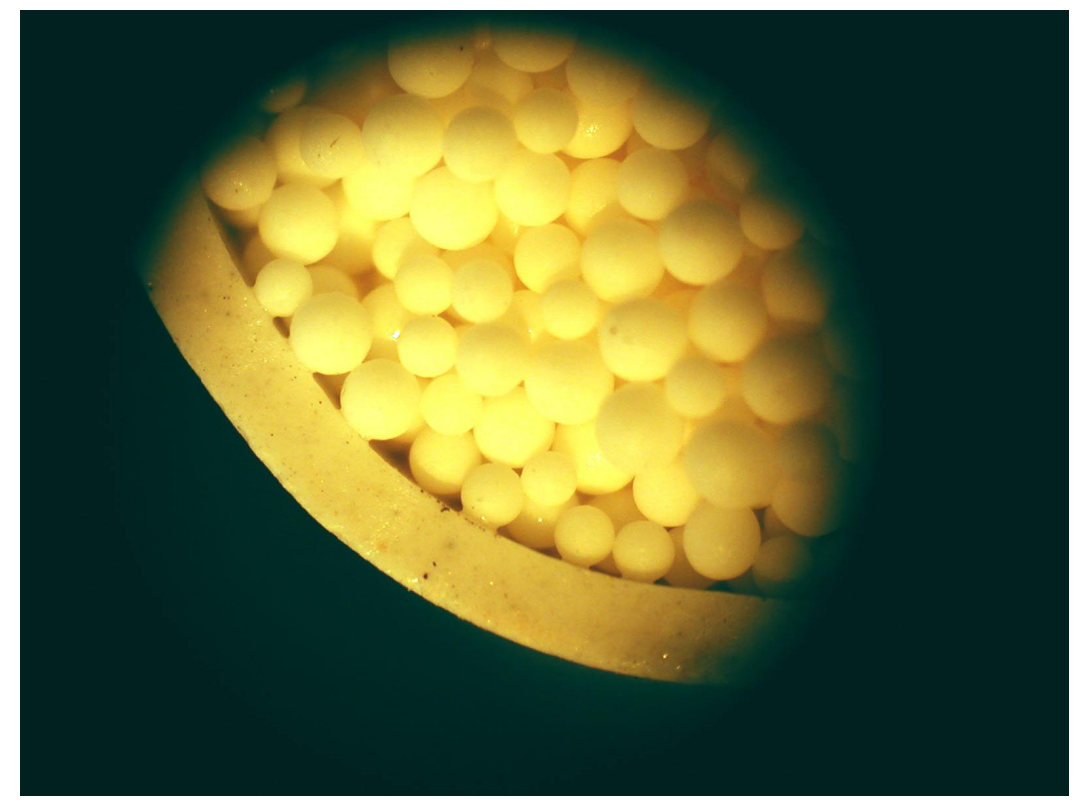

Figure 10. Interface between a 600 micron diameter microsphere filled isolator and its fully dense outer cylinder.

Thus, breakdown will tend to occur around the interface between the microspheres and the fully dense outer sleeve unless special measures are taken to cause the perimeter interface to be more complex or extended in actual path length.

The shielded negative terminal isolator concepts are specifically designed to inhibit conductive ceramic-to-metal seal atoms from migrating on the inner and/or outer surface of the isolators thus causing electrical leakage. The configuration imbeds the negative ceramic to metal seal into the alumina and can be used for high pressure cryobrake, porous filled configurations and wavy or grooved external surfaces.

As shown in Figs. 7 and 9, smaller particles and overall path length are important in preventing the initiation of breakdown and path length increases from hexagonal packed microspheres only adds $17 \%$ to the path length but only in the core of a porous particle filled isolator. Thus, it appears that the most promising porous particle-filled isolator would make use of a mixture of fine particles, alumina microspheres in a long path length such as an internal spiral. Such a combination would allow green stock firing shrinkage to match in the porous core and nonporous outer cylinder to match with significant inhibition of the buildup of avalanche breakdown through electron collision with closely spaced alumina surfaces.

\section{B. Electrical Insulators}

Two versions of electrical insulators were down-selected based on the criteria listed in the Apparatus and Procedure section. They are:

1. Wavy or grooved external surface ceramic-to-metal sealed alumina " $\mathrm{H}$ " cross section cylinder

2. Smooth external Wavy surface ceramic-to-metal sealed alumina "H" cross section

Both configurations are being fabricated for performance and durability evaluation. The wavy or grooved external surface insulator should be more durable to electrical breakdown from contamination caused by sputter deposition, arcing, spalled conductive flakes or pyrolyzed organic contamination. However, the tension, torsion, shear, and bending strength of both configurations exceed that of the NSTAR ion optics insulators as can be seen in Table II. This is important because of the heavier ion optics and probable larger launch vibration loads expected. 
Table II. Comparison of structural properties of the JIMO down-selected insulators with those for ion optics insulators on the NSTAR thruster.

\begin{tabular}{|l|c|c|c|c|c|c|c|c|}
\hline \multicolumn{1}{|c|}{ Design } & $\begin{array}{c}\text { Axial } \\
(\mathrm{lbs})\end{array}$ & $\begin{array}{c}\% \\
\text { Increase }\end{array}$ & $\begin{array}{c}\text { Bending, } \\
\text { lbs }\end{array}$ & $\begin{array}{c}\% \\
\text { Increase }\end{array}$ & $\begin{array}{c}\text { Shear, } \\
\text { lbs }\end{array}$ & $\begin{array}{c}\% \\
\text { Increase }\end{array}$ & $\begin{array}{c}\text { Torsion, } \\
\text { in-lb }\end{array}$ & $\begin{array}{c}\% \\
\text { Increase }\end{array}$ \\
\hline NSTAR & 6882 & 0 & 837 & 0 & 4371 & 0 & 1793 & 0 \\
\hline $\begin{array}{l}\text { JIMO- } \\
\text { Grooved Surface }\end{array}$ & 8572 & 24.6 & 2418 & 188.9 & 5444 & 24.5 & 3270 & 82.4 \\
\hline $\begin{array}{l}\text { JIMO- } \\
\text { Smooth Surface }\end{array}$ & 25715 & 273.7 & 2418 & 188.9 & 16333 & 273.6 & 6394 & 256.6 \\
\hline
\end{tabular}

Both of the configurations are double shadow shielded in accordance with the same design assumptions and guidelines for the isolators. Although the NSTAR optics insulators are simple hollow cylinders, the insulators under consideration for JIMO are " $\mathrm{H}$ " shaped in cross section. The purpose of the " $\mathrm{H}$ " cross section is to prevent any possibility of electrical breakdown on the inside of the insulators as a result of any conductive surface contamination from arcing, sputter deposition, metal migration or pyrolyzation of organic contamination from the spacecraft.

\section{Conclusion}

Design assumptions and guidelines were used to identify candidate Xe propellant isolator and insulator designs which are thought to be sufficiently conservative and robust to meet the needs of the proposed JIMO mission which greatly exceed those of the NSTAR Deep Space I mission. Down selection criteria were developed and used to identify eight isolator and two insulator designs for fabrication and evaluation. Preliminary testing of Paschen breakdown for various size particle filled isolators was performed as well as evaluation of issues associated with fabrication of porous filled isolators. Based on the evaluations and testing performed most promising isolator concepts appear to be porous particle filled isolators which make use of a mixture of fine particles, alumina microspheres in a long path length such as an internal spiral.

Insulators for both the screen grid and accelerator grid as well as thruster body are identical with two configurations being considered. The insulators exceed the mechanical properties of the NSTAR thruster and are " $\mathrm{H}$ " shaped in cross section to prevent electrical breakdown on the inside of the insulators.

\section{References}

${ }^{1}$ Rawlin, V.K., Pinero, L.R., Williams, G.J., and Roman, R.J., "Status of Ion Engine Development for High Power, High Specific Impulse Missions," 2001 International Electric Propulsion Conference, IEPC-01-096 Pasadena, CA, October 15-19, 2001.

${ }^{2}$ M.J. Schönhuber, IEEE Trans Power, App, and Sys, PAS-88 (1969) 100.

${ }^{3}$ R. Hackam, J. Phys. B, ser 2, vol. 2 (1969) 201. 
Public reporting burden for this collection of information is estimated to average 1 hour per response, including the time for reviewing instructions, searching existing data sources, gathering and maintaining the data needed, and completing and reviewing the collection of information. Send comments regarding this burden estimate or any other aspect of this collection of information, including suggestions for reducing this burden, to Washington Headquarters Services, Directorate for Information Operations and Reports, 1215 Jefferson Davis Highway, Suite 1204, Arlington, VA 22202-4302, and to the Office of Management and Budget, Paperwork Reduction Project (0704-0188), Washington, DC 20503.

\begin{tabular}{|l|l|l|}
\hline 1. AGENCY USE ONLY (Leave blank) & $\begin{array}{c}\text { 2. REPORT DATE } \\
\text { July } 2004\end{array}$ & $\begin{array}{c}\text { 3. REPORT TYPE AND DATES COVERED } \\
\text { Technical Memorandum }\end{array}$
\end{tabular}

\section{TITLE AND SUBTITLE} 5. FUNDING NUMBERS

Ultra High Voltage Propellant Isolators and Insulators for JIMO Ion Thrusters

\section{6. $\operatorname{AUTHOR(S)}$}

Bruce A. Banks, James R. Gaier, Ching-Cheh Hung, Patty A. Walters, Ed Sechkar, Scott Panko, and Christina A. Karniotis

\section{PERFORMING ORGANIZATION NAME(S) AND ADDRESS(ES)}

National Aeronautics and Space Administration

John H. Glenn Research Center at Lewis Field

Cleveland, Ohio 44135-3191

WBS-22-319-20-E1

\section{SPONSORING/MONITORING AGENCY NAME(S) AND ADDRESS(ES)}

National Aeronautics and Space Administration

Washington, DC 20546-0001

8. PERFORMING ORGANIZATION REPORT NUMBER

\section{E-14676}

11. SUPPLEMENTARY NOTES

Prepared for the 40th Joint Propulsion Conference and Exhibit cosponsored by the AIAA, ASME, SAE, and ASEE, Fort Lauderdale, Florida, July 11-14, 2004. Bruce A. Banks, James R. Gaier, and Ching-Cheh Hung, NASA Glenn Research Center; and Patty A. Walters, Ed Sechkar, Scott Panko, and Christina A. Karniotis, QSS Group, Inc., Cleveland, Ohio 44135. Responsible person, Bruce A. Banks, organization code 5480, 216-433-2308.

12a. DISTRIBUTION/AVAILABILITY STATEMENT 12b. DISTRIBUTION CODE

Unclassified - Unlimited

Subject Category: 23

Distribution: Nonstandard

Available electronically at http://gltrs.grc.nasa.gov

This publication is available from the NASA Center for AeroSpace Information, 301-621-0390.

13. ABSTRACT (Maximum 200 words)

Within NASA's Project Prometheus, high specific impulse ion thrusters for electric propulsion of spacecraft for the proposed Jupiter Icy Moon Orbiter (JIMO) mission to three of Jupiter's moons: Callisto, Ganymede and Europa will require high voltage operation to meet mission propulsion. The anticipated $\sim 6,500$ volt net ion energy will require electrical insulation and propellant isolation which must exceed that used successfully by the NASA Solar Electric Propulsion Technology Readiness (NSTAR) Deep Space 1 mission thruster by a factor of $\sim 6$. Xenon propellant isolator prototypes that operate at near one atmosphere and prototypes that operate at low pressures $(<100$ Torr) have been designed and are being tested for suitability to the JIMO mission requirements. Propellant isolators must be durable to Paschen breakdown, sputter contamination, high temperature, and high voltage while operating for factors longer duration than for the Deep Space 1 Mission. Insulators used to mount the thrusters as well as those needed to support the ion optics have also been designed and are under evaluation. Isolator and insulator concepts, design issues, design guidelines, fabrication considerations and performance issues are presented. The objective of the investigation was to identify candidate isolators and insulators that are sufficiently robust to perform durably and reliably during the proposed JIMO mission.

14. SUBJECT TERMS

Atomic interaction; Earth orbital environments

17. SECURITY CLASSIFICATION OF REPORT

Unclassified

\section{SECURITY CLASSIFICATION OF THIS PAGE \\ Unclassified}

19. SECURITY CLASSIFICATION OF ABSTRACT

Unclassified
15. NUMBER OF PAGES

16. PRICE CODE 20. LIMITATION OF ABSTRACT

Standard Form 298 (Rev. 2-89)

Prescribed by ANSI Std. Z39-18 298-102 

